\title{
AS TENSÕES ENTRE À EXPANSÃO E AS DESIGUALDADES SOCIAIS NO ACESSO AO ENSINO SUPERIOR EM MOÇAMBIQUE
}

https://dx.doi.org/10.5902/2318133868642

\author{
Leonel Elias Bene ${ }^{1}$ \\ Sebastião Juvêncio Rumbane ${ }^{2}$ \\ Fabiane Maia Garcia ${ }^{3}$ \\ Arminda Rachel Botelho Mourão4
}

\begin{abstract}
Resumo
Neste artigo aborda-se as tensões entre a expansão e as desigualdades sociais no acesso ao ensino superior em Moçambique. O estudo baseou-se em revisão bibliográfica e documental fundamentado em documentos oficiais e dados estatísticos do governo. As análises revelam que cresceu o quantitativo dos efetivos escolares, mas tal não significa que tenha favorecido a maioria dos que não tem condições de pagar. Concluímos que, com a abertura à privatização iniciada na década de 1990 e 2000, o ensino superior teve expansão e acesso fundamentado por uma política de diversificação das fontes de financiamentos instando a contribuição dos alunos por meio de pagamento de taxas e um fraco investimento dificultando a qualidade desejada pelas IES. Palavras-chave: ensino superior; políticas de acesso; políticas de expansão; Moçambique.
\end{abstract}

\section{TENSIONS BETWEEN EXPANSION AND SOCIAL INEQUALITIES IN ACCESS TO HIGHER EDUCATION IN MOZAMBIQUE}

\begin{abstract}
This article addresses the tensions between expansion and social inequalities in access to higher education in Mozambique. The study was based on a bibliographic and documentary review based on official documents and statistical data from the Government. The analyses reveal that the number of school staff has increased, but this does not mean that it has favoured the majority of those who are unable to pay. We conclude that with the opening to privatization initiated in the 1990s and 2000, Higher Education had expansion and access based on installing a policy of diversification of funding sources urging the contribution of students through payment fees and poor investment hindering the quality desired by higher education institutions.

Key-words: higher education; access policies; expansion policies; Mozambique.
\end{abstract}

\footnotetext{
${ }^{1}$ Universidade Púnguè - Extensão de Tete, Moçambique. E-mail: leonel.bene@gmail.com.

2 Escola de Jornalismo, Moçambique. E-mail: rsebastiaojuvencio@gmail.com.

3 Universidade Federal do Amazonas, Brasil. E-mail: fgarciaead@hotmail.com.

4 Universidade Federal do Amazonas, Brasil. E-mail: arachel@uol.com.br. 


\section{Introdução}

N este artigo trata-se do ensino superior em Moçambique e objetiva-se N discorrer sobre as tensões entre a expansão e as desigualdades sociais no acesso ao ensino superior. Para tal, faz-se uma breve caracterização histórica do ensino superior em Moçambique, focando nas condições que ditaram o seu surgimento, como se configurou o acesso ao longo do tempo e como é que se encontra a evolução dos efetivos escolares neste momento e que desafios enfrenta o ensino superior no país. Ao mesmo tempo, buscamos compreender os desafios impostos a sua qualidade, tendo como base a análise das políticas de expansão e acesso ao ensino superior que ocorreram no país.

Com uma história muito recente (1962), as instituições públicas do ensino superior em Moçambique enfrentam desafios que são atuais e presentes na maior parte das IES ao redor do mundo, desde a insuficiência de financiamento, condições de infraestruturas até a incapacidade de oferecimento do acesso aos desfavorecidos.

O Plano Estratégico do Ensino Superior - Pees - 2012-2020 (Moçambique, 2012b), define como uma das áreas a qualidade, expansão e o acesso. É neste sentido que julgamos ser fundamental perceber como é que se configura o acesso, a expansão e a qualidade do ensino superior em Moçambique, tendo em conta o previsto no plano estratégico que se afigura como uma das prioridades do governo. Na perspectiva do Pees, ao elencar o pilar acesso, expansão e qualidade,

toma-se em consideração a necessidade de crescimento e do imperativo de melhorar a qualidade do ES. Esta área tem como objetivo estratégico promover a expansão e o acesso equitativo ao ensino superior com padrões internacionais de qualidade, através de medidas que vão desde a diversificação das Instituições de Ensino Superior (IES), aumento do volume de bolsas de estudo, passando pela utilização de TIC e sistema de ensino à distância, até ao melhoramento na formação dos docentes e nas infraestruturas. (Moçambique, 2012b, p. 2 e 3)

É neste sentido que procuramos historicizar o ensino superior, analisar as estatísticas do acesso e verificar o nível de alcance desta ação, bem como analisar a sua expansão ao longo do tempo e como é que se configura a questão da qualidade do ensino superior. Nos propomos, ainda, a analisar o processo de expansão do ensino superior em Moçambique e a política de acesso e da avaliação da qualidade realizada pelo Estado. Trata-se de um estudo de carácter bibliográfico e documental. Utilizamos a revisão bibliográfica sobre ensino superior, quanto ao acesso, expansão e qualidade e em seguida fizemos o levantamento documental composto pela legislação geral do Sistema Nacional de Educação - SNE - sobre o subsistema do ensino superior moçambicano, os editais sobre 0 acesso ao ensino superior das IES públicas, bem como dados estatísticos disponíveis nos anuários do Ministério da Ciência e Tecnologia, Ensino Superior e Técnico Profissional, com a finalidade de confrontarmos esses dois pilares de dados, a literatura especializada e os documentos norteadores do ensino superior em Moçambique. A escolha pelas IES públicas em termos da análise dos dados de acesso tem a ver com o facto de todas elas oferecerem editais que indicam o número de novos ingressos perspectivados por cada ano acadêmico, o que é difícil de obter das IES privadas. 


\section{O ensino superior em Moçambique: histórico, acesso e expansão}

Historicamente, o surgimento do ensino superior em Moçambique é demarcado no ano de 1962, quando pelo decreto n. 44.530, de 21 de agosto, foram criados os Estudos Gerais Universitários de Moçambique - Egum - em resposta às críticas dos movimentos nacionalistas das colónias portuguesas (Moçambique, 2014, p. 4). Por meio do decreto-lei n. 43.779, de dezembro de 1968, foi criada a Universidade de Lourenço Marques - ULM e mais tarde com a Independência Nacional, a ULM foi transformada em Universidade Eduardo Mondlane - UEM -, com uma população estudantil nesta altura de 2.400 alunos distribuídos em diversos cursos.

Era suposto que o Egum se destinasse a uma elite negra para continuar a administrar o sistema colonial em África, mas não foi o que sucedeu, pois, esta instituição não absorveu a elite negra, de tal maneira que com a queda do regime colonial em meados da década de 1970, não se encontrava nas universidades, mas sim nas matas combatendo o colonialismo ou no exílio (Rosário, 2013). Ao longo do período que antecedeu a independência nacional, 0 ensino superior manteve um acesso discriminatório e excludente, pois, ao contrário do que ditou o seu surgimento, destinou-se maioritariamente aos filhos dos colonos (Mechisso, 2017, p. 9).

Após a Proclamação da Independência nacional um Estado socialista foi instalado e reformas foram efetuadas para garantir 0 acesso de todos a educação superior. A primeira década da independência (1975-1985) foi marcada por uma única universidade criada durante o período colonial, processo que veio a ser revertido só em 1985 e 1986, quando foram criadas duas IES. Nos referimos do Instituto Superior Pedagógico que, em 1995, se tornou em Universidade Pedagógica, hoje Universidade Pedagógica de Maputo, e o Instituto Superior de Relações Internacionais, hoje Universidade Joaquim Chissano (Silva, 2018; Mechisso, 2017; Noa, 2011).

A década de 1990 foi fundamental na expansão e no acesso ao ensino superior, pois este período foi marcado

com a viragem a que se vai assistir quer no país quer no mundo, nos inícios da década de 90 - queda do Muro de Berlim e fim da guerra fria, por um lado, e a adopção, por outro, no país de uma economia de mercado, de uma constituição liberal e o fim da guerra civil que deixaria marcas duradoiras de destruição a todos os níveis - ganha vulto um novo entendimento do papel do ensino superior. É, nesta conformidade, que em 1991 um diploma governamental institui, por exemplo, os exames de admissão ao ensino superior. (Noa, 2011, p. 227)

Gradualmente, depois da abertura à privatização iniciada durante a década de 1990 e 2000, o ensino superior foi seguido de expansão gradual aos números. O ensino superior é regulado no país por uma série de normas legislativas e uma delas é a Lei do Ensino Superior, aprovada pela Assembleia da República à 23 de setembro de 2009, trata-se da lei n. 27/2009. No entanto, desde a independência nacional em 1975, o país já experimentou três leis do ensino superior. A primeira foi a lei $n$. 1/93, que surgiu no ano seguinte ao da aprovação da lei n. 6/92, de 6 de maio, Lei do Sistema Nacional de 
Educação, que dentre vários aspectos ratificados afirma num dos seus princípios que "o Estado no quadro da Lei, permite a participação de outras entidades, incluindo comunitárias, cooperativas, empresariais e privadas no processo educativo" (Moçambique, 1992, p. 8).

Com esta abertura legal foram criadas condições para que provedores privados do setor educacional pudessem operar no campo da educação. Tal como se pode depreender, esta lei que é de base da educação em Moçambique, veio dentro do novo quadro político marcado pelo multipartidarismo e abertura a economia do mercado. Daí que Mandlate e Nivagara (2019) afirmam que "no contexto de uma economia de mercado, o ensino superior tornou-se num recurso não acessível a muitas famílias" (p. 30). É dentro deste novo viés que, como postula Rosário (2013), ocorre

a aprovação da Lei 1/93 - que estabelecia, pela primeira vez, um regime legal em que se abria espaço à entrada de operadores privados no estabelecimento de instituições de ensino superior em Moçambique - e a criação, em fevereiro de 1995, da Comissão Comiche - que tinha como missão refletir, estudar, conceber e propor ao governo uma política coerente sobre a expansão do ensino superior em Moçambique constituem as duas principais alavancas que tentavam dar uma nova dinâmica à problemática do ensino superior em nosso país. (p. 48)

Por outro lado, e de acordo com o que foi enunciado por Rosário (2013), Premugy (2012) afirma que

após a Independência de Moçambique, em 1975, e decorridos 15 anos, com a revisão da Constituição, em 1990, inicia-se a abertura para a economia do mercado e consequentemente a possibilidade de criação de instituições educacionais não mais sob a tutela do Estado - Neste contexto e com a primeira Lei sobre o Ensino Superior n. 0 1/93, de 24 de junho, é permitida a criação de instituições de ensino superior privadas e abre-se uma nova realidade de educação no país. (p. 5)

Ressaltamos que o ensino superior é considerado um subsistema pela lei que estabelece o regime jurídico do Sistema Nacional de Educação em Moçambique, abreviadamente designado de Lei do SNE. De acordo com a mesma, constituem suas competências "assegurar a formação ao nível mais alto nos diversos domínios do conhecimento técnico, científico e tecnológico necessário ao desenvolvimento do país" (Moçambique, 2018a, p. 23) e só podem ingressar no ensino superior os graduados da $12^{\text {a }}$ Classe do Ensino Geral ou equivalente.

De acordo com a Lei do Ensino Superior, as IES classificam-se em "universidades, institutos superiores, escolas superiores, institutos superiores politécnicos e academias" (premugy, 2012, p. 32). Até março de 2019 existiam em Moçambique 53 IES, dentre públicas e privadas. Destas 19 são universidades, 27 são instituto superiores entre politécnicos ou não, 4 escolas superiores e 3 academias. Notamos, com base nos dados gerais extraídos do portal do MCTESTP, a predominância de IES privadas no país. Até o momento não existe nenhuma academia privada que tenha sido criada ou autorizada a funcionar e há uma paridade em termos de escolas superiores sendo de duas cada, tabelas 1 e 2 . Enquanto corporizávamos o presente artigo decorria no país um processo de restruturação da segunda IES mais antiga do país - Universidade Pedagógica - e da 
restruturação deu origem a cinco novas universidades: Universidade Pedagógica de Maputo, Universidade Save, Universidade Púnguè, Universidade Licungo e Universidade Rovuma.

Tabela 1 -

Distribuição de IES por classificação.

\begin{tabular}{c|c|c|c}
\hline Classificação & N. de IES públicas & N. de IES privadas & $\begin{array}{c}\text { N. total de IES } \\
\text { públicas e privadas }\end{array}$ \\
\hline Universidades & 9 & 10 & 19 \\
\hline Institutos & 8 & 19 & 27 \\
\hline Escolas & 2 & 2 & 4 \\
\hline Academias & 3 & - & 3 \\
\hline Total & 22 & 31 & 53 \\
\hline
\end{tabular}

Fonte: MCTESTP5.

Tabela 2 -

Estudantes matriculados desde 2003-2017.

\begin{tabular}{c|c|c|c|c}
\hline \multirow{2}{*}{$\begin{array}{c}\text { Matriculados por } \\
\text { ano }\end{array}$} & \multicolumn{2}{|c|}{ IES } & \multirow{2}{*}{ Total } & \multirow{2}{*}{ Variação \% } \\
\cline { 2 - 3 } 2003 & Pública & Privada & & 0 \\
\hline 2004 & 11235 & 5990 & 17225 & 29,20 \\
\hline 2005 & 15113 & 7143 & 22256 & 27,14 \\
\hline 2006 & 18863 & 9435 & 28298 & 52,77 \\
\hline 2007 & 31922 & 11311 & 43233 & 46,82 \\
\hline 2008 & 51001 & 12475 & 63476 & 11,44 \\
\hline 2009 & 58643 & 12099 & 70742 & 28,00 \\
\hline 2010 & 60949 & 20301 & 81250 & 29,82 \\
\hline 2011 & 75705 & 29778 & 105483 & 7,56 \\
\hline 2012 & 80010 & 33454 & 113464 & - \\
\hline 2013 & - & - & - & - \\
\hline 2014 & - & - & - & 38,74 \\
\hline 2015 & 104979 & 52452 & 157431 & 11,03 \\
\hline 2016 & 116037 & 58765 & 174802 & 12,58 \\
\hline 2017 & 119522 & 77279 & 196801 & 0 \\
\hline
\end{tabular}

Fonte: MCTESTP 6.

Com base nas buscas feitas no site do MCTESTP, não foi possível encontrar dados de 2012 e 2013, por este motivo não se encontram disponíveis na tabela. Contudo, a apresentação de dados a partir de 2003 tem a ver com o fato de não terem sido achados dados de anos anteriores no site do MCTESTP, que foi o motor principal de buscas para a elaboração da tabela 2. Assim sendo, a nossa análise começará, com particular incidência neste período, sem deixar de lado os momentos iniciais do ensino superior no país.

${ }^{5}$ Lista de IES atualizada 26/03/2019. Disponível em http://www.mctestp.gov.mz/por/Ensino-

Superior/Instituicoes-de-ES/Instituicoes-de-ES. Acesso em: 6 jun. 2019.

6 Dados disponíveis em http://www.mctestp.gov.mz/por/Ensino-Superior/Dados-Estatisticos Acesso em: 6 jun. 2019. 
De acordo com o anuário estatístico de 2004, o processo de elaboração de dados estatísticos nacionais sobre o ensino superior se encontra em elaboração (Moçambique, 2005 , p. i). Das lacunas existentes, uma é a inexistência de dados no portal de informações relativas aos anos anteriores à 2003 e os dados de 2012 e 2013, que ainda não se encontram disponíveis no mesmo portal.

Com base nos dados constantes na tabela 2, de 2013 a 2017 nota-se um crescimento da população estudantil frequentando o ensino superior. As IES públicas, apesar de se apresentarem em número reduzido, são as que oferecem mais vagas. $O$ ensino superior público chegou a oferecer mais de 15 mil vagas anuais nos últimos cinco anos (Mechisso, 2017; Universidade Pedagógica, 2017a, 2017b, 2018; UEM, 2018, 2017; Isri, 2018, 2017). Embora os números testemunhem uma expansão, o acesso ao ensino superior é ainda limitado, pois com uma população total de 20,2 milhões de habitantes registados no censo de 2007, apenas 1,9\% tinham acesso a ele (Martins, 2011 apud Silva, 2018, p. 216). Analisando os dados que são fornecidos pelo MCTESTP, de 2017, dos efetivos de estudantes no ensino superior e do Instituto Nacional de Estatística - INE , relativo ao censo populacional de 2017, Moçambique está com uma população de 27,9 milhões de habitantes e os dados nos informam que até 2017 menos de $1 \%$ da população teve acesso ao ensino superior $(0,7 \%)$. Isto nos revela que apesar do aumento em termos de vagas, o acesso não acompanhou o crescimento populacional, pois em dez anos tivemos uma redução em termos percentuais no acesso.

O Plano Estratégico do Ensino Superior (2012-2020), previa "promover a participação e o acesso equitativos, ao ensino superior" (Moçambique, 2012b). A olhar pelos números até aqui apresentados, ainda que sejam vagas oferecidas por IES públicas, acima de $60 \%$ destas é para quem tem capacidade de pagar e as aulas decorrem na maioria das instituições no período noturno ou na modalidade de educação aberta e à distância. Apesar dos números estarem a sugerir um crescimento em termos de ingressos, continuamos com um ensino superior elitista ao excluir boa parte dos moçambicanos que não tem capacidade de pagar as taxas praticadas por estas instituições e por estas estarem instaladas nos grandes centros urbanos.

Observando os dados apresentados na tabela 2 é possível perceber que o ano de 2006 foi o período de virada em termos de acesso ao ensino superior. Quase duplicou o número de estudantes quando comparado com o ano anterior e isto deveu-se a abertura de maior número de cursos no período noturno ou pós-laboral por parte das IES (Gonçalves, 2018). Este período é caracterizado como afirma Rosário (2013, p. 46), de "expansão contínua e sem critério". De 5 para 44 IES e de 10 mil estudantes para 120 mil ao longo de 13 anos, entre 1997 e 2010.

No quadro da declaração de prioridade absoluta a problemática do ensino superior e a consciência estatal de que "investir na educação é investir muito alto", não tendo feito este investimento e em violação à Lei do Ensino Superior então aprovada em 1993 que estabelecia etapas para a entrada em funcionamento das IES, "o Estado começa a licenciar instituições de ensino superior privadas e ocorre a abertura de delegações de ensino superior público, de uma forma a-criteriosa" (Rosário, 2013, p. 49). A abertura do ensino superior ao mercado pode ser compreendida como uma estratégia usada pelo 
Estado para, por um lado garantir o acesso ao ensino superior por meio da sua expansão no território nacional e, por outro, o Estado gradualmente limitar seu financiamento às IES, orientando que estas adoptem formas de cobrar taxas ou mensalidades aos estudantes para suportar suas despesas de formação.

Apesar da evolução registada em termos de acesso e expansão, é preciso considerar tal como é relatado por Mechisso (2017), que "o crescimento em número de IES não foi acompanhado, em paralelo, com a construção de infraestruturas como moradias e restaurantes estudantis para garantir a assistência ao número crescente de estudantes no ensino superior" (p. 41). Este fato continua sendo uma limitação para que sujeitos oriundos de regiões distantes dos centros urbanos tenham acesso ao ensino superior. Outra questão não menos importante que as IES promovem é o aumento de acesso ao ensino superior, mas sem adoptar formas de incentivo para abrangência dos mais desfavorecidos, e assim sendo, acabam por ampliar o acesso para os que tem capacidade de pagar as despesas de formação enraizando-se cada vez mais a exclusão social no acesso ao ensino superior em Moçambique.

No entendimento de Mandlate e Nivagara (2019) essa situação revela "a incapacidade financeira de muitas famílias das províncias de arcar com as despesas de estudos dos seus filhos fora do seu meio familiar" (p. 29). Mesmo assim, tal como é revelado por Noa (2011), "Moçambique está entre os países em que a implantação do ensino superior é nitidamente fraca" (p. 231), sobretudo quando se olha para a proporção número total de habitantes do país e estudantes inscritos no ensino superior.

Apesar deste reconhecimento numérico, o ministro chamou a atenção, segundo a mesma fonte, para o fato de que "a rede de ensino superior deve ser mais alargada, mas não de forma apressada, pois "a rápida expansão do ensino superior pode trazer problemas na sua qualidade" (Noa, 2011, p. 231. O que, aparentemente, não veio a acontecer a olhar pelas estatísticas que são apresentadas na tabela 2, se afigurando como um ensino que se centra na formação de técnicos qualificados para o mercado de trabalho, com pouco interesse na formação de acadêmicos com maior visão crítica e que possam contribuir para harmonia social.

Para além do aumento das IES, e na tentativa de reduzir as assimetrias em termos de acesso ao ensino superior, uma das ações conduzidas pelo governo moçambicano foi a implantação, no ano de 2002, de um programa de Bolsas de Estudos Provinciais, com propósito não só de expandir o acesso, mas o financiamento de sujeitos que jamais conseguiriam acessar ao ensino superior, mas com a obrigatoriedade do regresso dos bolseiros às províncias de origem (Noa, 2011). A efetividade deste programa foi questionada por um estudo encomendado pelo então Ministério da Educação e Cultura à Ernest \& Young, uma vez que boa parte dos estudantes não regressaram as regiões de origem tal como o programa preconizava por diversas razões, como é o caso das regiões de procedência não terem capacidade de absorver o sujeito retornado por conta da incapacidade das economias locais de os contratar e pelo facto de que o programa tendia "a beneficiar estratos sociais das zonas urbanas" (Noa, 2011, p. 233). Dados não menos importantes estão relacionados com as disputas das vagas que são oferecidas pelas IES públicas, uma vez que são elas que deveriam oferecer vagas a todos, numa perspectiva de justiça social. 
Com este fato percebemos o que Ivashita, Novak e Bertolleti (2009) entendem quando afirmam que "a influência das agências de financiamento internacionais no que se refere às medidas empregadas ao ensino superior tem focado a diminuição dos gastos dos setores públicos" (p. 9359). Ao que nos parece, por meio desta influência, ocorre um reposicionamento das IES no sentido de tal como entende Sguissard (2000) de proceder "incremento à integração com a economia mundial, a ênfase no papel do mercado na alocação de recursos, a diminuição do papel do Estado com relação tanto a economia quanto à área social dos serviços públicos em que se insere a educação superior" ( $p$. 9359). Estes não se encontram isolados da assunção do Banco Mundial (1997), quando afirma que

embora o Estado ainda tenha um papel central na provisão e garantia de serviços básicos - educação, saúde e infra-estrutura -, não é óbvio que deva ser o único provedor, ou mesmo que seja provedor. As decisões do Estado em relação à provisão, financiamento e regulamentação desses serviços devem basear-se nas vantagens relativas dos mercados, da sociedade civil e dos órgãos do governo. (Banco Mundial, 1997, p. 28)

Outro dado, encontrado no terceiro objetivo estratégico do Pees, tem a ver com o fato de que

as infra-estruturas devem ser adequados às actividades académicas, foi estabelecido, como objectivo estratégico, melhorar o financiamento para o funcionamento e estabelecimento de infra-estruturas adequadas para actividades académicas, através de acções tais como a introdução de formas diferenciadas de financiamento, incluindo a comparticipação das famílias, a geração de renda pela IES. (Moçambique, 2012b, p. 3)

Este argumento defendido no Pees coloca em xeque o dever do Estado de prover recursos necessários ao funcionamento e desenvolvimento das atividades nas IES e coloca numa situação mais complicada os que não tem capacidade de pagar. Mesmo reconhecendo no Pees 2012-2020 o "decréscimo de rendimentos e consequente incapacidade de as famílias financiarem os estudos dos seus filhos" (Moçambique, 2012b, p. 12), o Estado não abandona a ideia de isentar o pagamento de taxas no ensino superior fazendo com que este nível de ensino se destine a indivíduos com recursos financeiros, pois estes têm capacidades para efetuarem os pagamentos das propinas e taxas instituídas pelas IES. Desta forma, os detentores de poder que também constituem a minoria elitista em Moçambique, pagam a formação dos seus filhos, preparando sua futura empregabilidade e garantia de continuidade nas posições políticas, econômicas e sociais.

Ao proceder deste modo, fica limitada a possibilidade do acesso ao ensino superior e, consequentemente o direito a esta educação, o que no entender de Silva (2004) "a educação é um direito humano durante toda a vida, sendo obrigatória para quem tem a responsabilidade de a favorecer - o Estado e os parceiros sociais - e gratuita para que 0 direito se alargue a todos os indivíduos" (p. 2). A argumentação trazida pelo Estado encontra sintonia com o que vem sendo defendido pelo Banco Mundial (1995), de que não se deveria proibir as escolas públicas de obter recursos das comunidades locais, quando o financiamento público é insuficiente. Por um lado, a Unesco (2009), mesmo reconhecendo que a educação é um bem público, recomenda que o 
financiamento privado deve ser estimulado. Enquanto todos os esforços devem ser tomados para aumentar o financiamento público do ensino superior, é necessário reconhecer que os financiamentos públicos são limitados e podem não ser suficientes para desenvolver o setor rapidamente. Outras fórmulas e fontes de financiamento devem ser encontradas, especialmente as baseadas no modelo de parceria públicoprivado. (p. 6)

O Banco Mundial não concorda que sejam dados passos no sentido de isentar estas taxas, em virtude de entenderem que subsidiar os estudantes "de universidades públicas constitui não apenas um investimento educacional ineficiente, como também um gasto social regressivo (Banco Mundial, 1995, p. 2), propondo, deste modo, a que o maior investimento seja realizado ao nível da educação básica. É assim que o país acolhe as propostas veiculadas pelo Banco Mundial circunscritas na ideia "de que o retorno individual e social dos recursos públicos investidos em educação superior era muito inferior ao dos investidos na educação básica [e] de que a universidade de ensino e não a universidade de pesquisa ou conhecimento era a ideal para países em desenvolvimento" (Sguissardi, 2008, p. 859).

\section{A expansão do acesso ao ensino superior e os desafios impostos a sua qualidade}

Dados do ensino superior em Moçambique, expressos no anuário estatístico de 2012, indicam que "o ensino superior aumentou rapidamente de cerca de 12 mil estudantes, em 2000, para mais de 101 mil, em 2010. Este crescimento numérico coloca desafios à qualidade do ensino e ao funcionamento das instituições de ensino dos diferentes níveis" (Moçambique, 2012b, p. 2).

É importante destacar que é impossível ter uma definição precisa do que vem a ser a qualidade, pois tal como é afirmado por Sguissardi (2006) "qualidade é daqueles termos polissêmicos, ou camaleônicos, que mimetizam significados e cores do contexto que os produz ou que condiciona sua existência" (p. 71). Contudo, vale destacar na ótica do mesmo autor, que "a tendência atual é de associá-la a avaliação e/ou acreditação, o que envolve necessariamente o Estado, isto é, o chamado Estado Avaliador. Mas se associa também e de forma ostensiva a competitividade e empregabilidade" (Sguissardi, 2006, p. 70).

Convém referir que a avaliação da qualidade em Moçambique tem sido, sobretudo, quantitativa e menos qualitativa, pois as IES pouco contribuem na resolução dos problemas sociais e nem na descoberta e inovação. Perante esta situação, Terenciano e Natha (2016) elucidam que, "a utilização excessiva de informações quantitativas, como base de avaliação do ensino superior, além de pressionar os indivíduos para alcançarem determinados indicadores quantitativos, não é capaz de garantir que se avalie a qualidade" (p. 81). Sendo, portanto, fundamental a combinação dos indicadores quantitativos e qualitativos quando se avalia a qualidade do ensino. No entanto, a qualidade da educação, no entendimento de Dourado, Oliveira e Santos (2007), 
é definida com relação aos recursos materiais e humanos que nela se investem, assim como em relação ao que ocorre no âmbito da instituição escolar e da sala de aula, seja nos processos de ensino e aprendizagem, seja nos currículos e nas expectativas com relação à aprendizagem dos alunos. (p. 12)

As instituições do ensino superior moçambicanas carecem de recursos, tanto materiais, quanto humanos qualificados para garantir a expansão, o acesso ao ensino de qualidade e estarem em condições de com base nos respectivos quadros conceber currículos que contribuam para resolução dos problemas sociais. O caráter de expansão do ensino superior que se regista em Moçambique põe em questão a situação da regulação estatal por um lado, e por outro a questão da avaliação qualitativa das instituições e a formação em curso nestas IES. Por este motivo, é preciso destacar que, com a lei n. 1/93, a questão da qualidade ainda não havia se afigurado como fundamental. $O$ que se queria neste momento, por conta das pressões relativas à assimetria em termos de acesso ao ensino superior era garantir esta expansão ainda que de forma a-criteriosa como afirma Rosário (2013).

A segunda Lei do Ensino Superior, a lei n. 5/2003, de 21 de janeiro, visou, entre outros aspectos, ao controle da qualidade (Premugy, 2012). Para responder ao desiderato da qualidade prevista nesta lei, um decreto foi aprovado pelo Conselho de Ministros, o decreto n. 63/2007, de 31 de dezembro, que instituiu o Sistema Nacional de Avaliação, Acreditação e Garantia de Qualidade do Ensino Superior. Para (Premugy, 2012), este quadro legal foi justificado "com a crescente expansão de Instituições de Ensino Superior aliada à necessidade de harmonização do ensino superior a nível nacional, regional e internacional o que remete a necessidade do estabelecimento de mecanismos que assegurem a melhoria da qualidade e relevância dos serviços prestados" (p. 10). O regulamento surgiu num contexto em que o número de estudantes de ensino superior quase duplicou em 2006 com a expansividade para os cursos noturnos. Começa-se, desde este período, com o ciclo de preocupação com a qualidade da educação superior no país:

A tutela despertou, após esse período de expansão rápida, promovendo trabalhos de elaboração e sistematização de regulamentos de natureza universitária e produção de instrumentos regulamentares que permitam a avaliação das instituições de ensino superior e a sua acreditação. Simultaneamente, a tutela adotou também posturas regulamentares que permitem a circulação de docentes e discentes interna e internacionalmente. (Rosário, 2013, p. 50)

Ainda num outro trecho, o mesmo autor assume que este quadro só pode ser revertido diante de ações enérgicas do governo, com base no financiamento quer seja para o ensino superior público, assim como para o privado: "Não há financiamento não há qualidade. Na falta de qualidade, falta financiamento. A conjugação desses dois fatores promove um país com cidadãos pouco atentos à própria realidade. É uma questão de soberania" (Rosário, 2013, p. 53). Esse entendimento do que é desejável para que se alcance a qualidade, é fragilizado logo quando o Estado moçambicano aloca ao sector de educação cerca de $20 \%$ do seu orçamento. Mesmo com um reconhecimento por parte do governo de que "o incremento da qualidade exige a alocação de maiores volumes de 
recursos ao ensino superior que actualmente apenas beneficia de perto de $15 \%$ do orçamento da educação" (Moçambique, 2012b, p. 7), esta preocupação começa a ganhar notoriedade com

o lançamento, em 2000, do Plano Estratégico do Ensino Superior em Moçambique 2000-2010 e a criação do Ministério do Ensino Superior, Ciência e Tecnologia (MESCT), [que] seriam reveladores do compromisso do Estado em relação aos grandes desafios que se colocavam ao próprio subsistema (expansão do acesso, relevância e qualidade), às políticas a perseguir para responder ao crescimento e à complexidade que aí se verificavam. (Noa, 2011, p. 227)

O Plano Estratégico do Ensino Superior em Moçambique 2000-2010 foi fundamental para permitir o acesso ao ensino superior na perspectiva do autor supramencionado. Mesmo assim, no entendimento do mesmo autor assiste-se "uma deterioração gradual da qualidade dos processos e, consequentemente, dos produtos" (Noa, 2011, p. 227), por conta do que Rosário (2013) chama de expansão a-criteriosa e Noa (2011) como um período de contradições, tensões, indefinições, desvios e perversões.

Como se pode depreender, foi no segundo período de vigência do Plano Estratégico do Ensino Superior que se aprovou a lei que instituiu o Sistema Nacional de Avaliação, Acreditação e Garantia de Qualidade do Ensino Superior. Neste quadro e, como forma de resposta ao grito que vinha de diferentes estratos sociais da sociedade moçambicana, 0 governo tomou a decisão de

suspender o licenciamento de novas instituições de ensino devido à manifesta falta de qualidade patenteada por muitas delas. Nessa constatação e nessa decisão tardia, o que prevalece, segundo as próprias autoridades, é a preocupação em encontrar um instrumento que assegure o cumprimento de padrões mínimos de qualidade tanto no licenciamento como no funcionamento das instituições. (Noa, 2011, p. 228)

Como resultado da ação do Estado tentando forçar um ensino superior normal e de qualidade, assistimos, no ano de 2018, o encerramento de IES que se apresentavam sem condições mínimas para funcionar. Estando todas elas em funcionamento e de acordo com o Ministro que tutelava o ensino superior citado pelo Jornal Notícias de 6 de fevereiro de 2018, verificadas as irregularidades, 28 IES, incluindo delegações, foram interditas de admitir novos estudantes (Notícias, 2018). Os efeitos desta medida foram mais longe quando, em finais do ano 2018, algumas IES/delegações delas foram encerradas.

Como resultado do cumprimento das matrizes de avaliação que foram destacadas para serem melhoradas nas inspeções realizadas pelo MCTESTP, volvidos um tempo, algumas delas, ainda que tenham cumprido as exigências mínimas, foram autorizadas a funcionar tal como foi proferido pelo ex-ministro da Ciência e Tecnologia, Ensino Superior e Técnico profissional em entrevista dada a STV ${ }^{7}$ aquando da cerimónia de graduação de mais de mil estudantes do Instituto Superior Mutasa, em Manica:

7 Grupo Soico, uma rede de mídia em Moçambique.

\begin{tabular}{l|l|r} 
Regae: Rev. Gest. Aval. Educ. & Santa Maria & v. 11
\end{tabular}

\begin{tabular}{l|l} 
v. 11 & n. 20
\end{tabular}

e68642, p. 1-16

2022 
Na verdade, quando nós fizemos a ronda pelo país, nós constatamos que 28 instituições não tinham condições de ter alvará. E, nós demos o prazo de 1 ano para as instituições conformarem-se com a lei. Então, das 28, 16 conformaram-se com a lei, 12 não se conformaram e nós não atribuímos alvarás. Eu queria aqui publicamente reconhecer o trabalho que foi feito pelo Mutasa, porque o Mutasa estava no grupo das 28, mas o Mutasa fez o trabalho que devia fazer e nós concedemos o alvará como bem disseram em dezembro do ano passado. (Jorge Nhambiu, ex-Ministro da Ciência e Tecnologia, Ensino Superior e Técnico Profissional em entrevista a STV) ${ }^{8}$

Este dado é revelador de que a instituição melhorou em alguns aspetos no tocante as constatações que ditaram o seu encerramento e muito focado principalmente ao ensino, descurando os outros dois pilares do ensino superior, que é a pesquisa e a extensão. Contudo, é preciso reafirmar que com as ações do ministério tendentes a melhorar a qualidade, os decretos que foram aprovados deixam de ser uma letra morta, sem nenhuma aplicabilidade como instrumento regulador nem na abertura e nem no funcionamento das instituições e começamos a notar uma preocupação com a possibilidade de assegurar maior qualidade dos processos científicos, pedagógicos e administrativos e, por conseguinte por uma busca dos produtos de excelência de que tanto se encontra carenciada a sociedade no seu todo (Noa, 2011, p. 234).

Notamos, porém, uma preocupação desde a aprovação do Pees 2012-2020 com a questão da qualidade, pois já era constatado nesta altura de que "o ensino superior enfrentaria na presente década 2011-2020 desafios orientados para a sustentabilidade e garantia da qualidade em resposta à necessidade de um maior controle da expansão ocorrida na década 2000-2010" (Moçambique, 2012a, p. 7). Há um esforço que vai sendo realizado no sentido de garantir esta qualidade. Há uma posição mais atuante desde 2017 para cá e as IES que não oferecem as condições necessárias vão sendo retiradas dos radares. Mesmo assim, continuam os desafios, de forma particular na questão da melhoria dos indicadores de qualidade em boa parte das IES na questão da pesquisa e extensão universitária. Hoje parece que as ações do executivo estão voltadas ao ensino apenas.

É notável em Moçambique o distanciamento entre o que as universidades têm desenvolvido e os problemas que assolam a sociedade. Há, pois, a necessidade de o ensino superior estar voltado também para a pesquisa, de modo que na comunidade acadêmica seja desenvolvido o pensamento crítico com enfoque na inovação e resolução dos problemas que dificultam o bem-estar social.

\section{Considerações finais}

Ainda que tenha ocorrido a expansão e o consequente incremento da população estudantil, o ensino superior continua sendo uma miragem para a maioria da população moçambicana, em virtude da maioria das IES estarem localizadas nas cidades capitais das províncias. Este crescimento e expansão, precedida do acesso de que se faz menção

\footnotetext{
${ }^{8}$ Entrevista disponível no Programa Noite Informativa de 14 de junho. Disponível em: https://www.youtube.com/watch?v=kfEoKUZjHSI. Acesso em: 15 jun. 2019.
} 
neste texto, não foi acompanhada da construção de infraestruturas de assistência estudantil, como é o caso de lares estudantis e restaurantes universitários, que poderiam funcionar apoio para os estudantes deslocados de suas áreas habitacionais.

Ainda que tenha registado um crescimento acelerado de IES e número de estudantes nos últimos anos, continua em debate a qualidade destas instituições. Por mais que o acesso e a expansão tenham sido melhorados nos últimos anos, continua evidente que, em Moçambique, o ensino superior não é acessível para a maioria dos alunos que terminam o ensino secundário por várias razões: a primeira é a capacidade muito limitada de absorção dos candidatos a este nível de ensino, e a segunda é a cobrança de taxas que tornam a frequência do ensino superior menos acessível à maioria das famílias de menor renda.

As IES públicas se preocupam cada vez mais pelo interesse privatista das vagas por si ofertadas, o que vem a cimentar a tendência excludente. Outrossim, apesar desta expansão, percebemos que, em termos de distribuição geográfica dos cursos oferecidos pelas IES que, Maputo, Beira, Nampula são as cidades que oferecem maior diversidade de ofertas formativas, impedindo possibilidades de escolha para quem está fora destas.

O financiamento tem de ser percebido como elemento chave para a melhoria da qualidade. Um financiamento não só para responder a questões de infraestrutura, mas que vise aos três pilares do ensino superior. Há uma tendência a renúncia do Estado em prover a educação superior quando assume que a diversificação das fontes de financiamento tem de ter a comparticipação das famílias, quando a maioria das famílias não tem capacidade de pagar. Isto passa a funcionar como um critério de exclusão para boa parte dos moçambicanos.

Ocorreu a implantação de programas de bolsas de estudo provinciais, que podem ter sido um fracasso, pois ao longo dos seus períodos de implantação acabaram não absorvendo a indivíduos de regiões rurais. As entidades receptoras das documentações para o concurso da mesma estão nas capitais provinciais e o sistema de divulgação dificultava o acesso à informação. Recentemente foi inaugurada a página do Instituto de Bolsas de Estudo de Moçambique o que pode contribuir para que mais moçambicanos fora de Maputo e das capitais provinciais tenham possibilidades de participar de processos de candidatura a bolsa de estudos.

Entendemos, por outro lado, que o que poderia contribuir para a qualidade do ensino superior moçambicano, resguardadas as circunstâncias de ordem institucional, são as novas exigências e termos de qualificação e regime de trabalho dos docentes, o que passaria por estes se dedicarem no desempenho das atividades acadêmicas na instituição de ensino onde estão vinculados. O que passa necessariamente por o Estado moçambicano formar mais docentes e melhorar as condições salariais e de trabalho.

Não podemos ignorar que tenham sido feitos avanços, mas poderíamos fazer mais para que a constatação que foi realizada pelo Banco Mundial há mais de 33 anos se mostre presente na realidade do país quando afirmou que "o ensino superior em África é um luxo" (Silva, 2018, p. 214) e Moçambique é parte integrante desta realidade. 


\section{Referências}

BANCO MUNDIAL. Relatório sobre desenvolvimento mundial 1997: o Estado num mundo em transformação. Washington: Banco Mundial, 1997.

CRUZ, Rosana Evangelista da. Banco Mundial e política educacional: cooperação ou expansão dos interesses do capital internacional? Educ. Rev, Curitiba, n. 22, 2003, p. 5175.

DOURADO, Luiz Fernandes; OLIVEIRA, João Ferreira de, SANTOS, Catarina de Almeida. A qualidade da educação: conceitos e definições. Brasília: Inep, 2007.

ENSINO SUPERIOR: Vinte e oito instituições em risco de fechar as portas. Jornal Notícias, Maputo, 5 fev. 2018. Disponível em http://www.jornalnoticias.co.mz/index.php/politica/75810-ensino-superior-vinte-e-oitoinstituicoes-em-risco-de-fechar-as-portas.html. Acesso em: 13 jun. 2019.

GONÇALVES, António Cipriano Parafino. O direito à educação e políticas de expansão do ensino superior público em Moçambique: estagnação, privatização e exclusão (19862008). Avaliação, Campinas, v. 23, n. 1, 2018, p. 37-57.

INE. Apresentação dos resultados definitivos do vi recenseamento geral da população e habitação 2017. Maputo: INE, 2019.

INSTITUTO SUPERIOR DE RELAÇÕES INTERNACIONAIS. Edital para exames de admissão para o ano lectivo 2018. Maputo: Isri, 2017.

INSTITUTO SUPERIOR DE RELAÇÕES INTERNACIONAIS. Edital para exames de admissão para o ano lectivo 2019. Maputo: Isri, 2018.

IVASHITA, Simone Burioli; NOVAK, Maria Simone Jacomini; BERTOLLETI, Vanessa Alves. O Ensino Superior na perspectiva do Banco Mundial: algumas considerações. CONGRESSO DE NACIONAL DE EDUCAÇÃO - EDUCERE, 9, 2009. Anais ... Curitiba: PUCPR, 2009.

MANDLATE, Ernesto; NIVAGARA, Daniel. Políticas de acesso ao ensino superior em Moçambique: progressos e desafios da sua implementação. Educamazônia-Educação, Sociedade e Meio. Ambiente, Manaus, v. 22, n. 1, 2019, p. 7-34, 2019.

MECHISSO, Guedes Basílio. Políticas de assistência estudantil no ensino superior em Moçambique: passado, presente e desafios. Porto Alegre: Ufrgs, 2017. 156f. Tese (Doutorado em Educação). Universidade Federal do Rio Grande do Sul.

MOÇAMBIQUE. Lei n. 18/2018 de 28 de dezembro: estabelece o regime jurídico do Sistema Nacional de Educação na República de Moçambique. Maputo: Boletim da República, 2018a.

MOÇAMBIQUE. Lei n. 1/2018 de 12 de junho: Lei da Revisão Pontual da Constituição da República de Moçambique. Maputo: Boletim da República, 2018b.

MOÇAMBIQUE. Dados estatísticos sobre o ensino superior, 2015. Maputo: Ministério da Ciência e Tecnologia, Ensino Superior e Técnico Profissional, 2016.

MOÇAMBIQUE. Pesquisa sobre ciência, engenharia, tecnologia e inovação: instrumentos de política, órgãos, quadro legal e políticas. Maputo: Ministério da Ciência e Tecnologia, 2014.

MOÇAMBIQUE. Dados estatísticos sobre o ensino superior, 2011. Maputo: Ministério da Educação, 2012a.

MOÇAMBIQUE. Plano estratégico do ensino superior 2012-2020. Maputo: Mined, 2012b.

\begin{tabular}{|l|l|l|l|l|l|}
\hline Regae: Rev. Gest. Aval. Educ. & Santa Maria & v. 11 & n. 20 & e68642, p. 1-16 & 2022 \\
\hline
\end{tabular}


MOÇAMBIQUE. Dados estatísticos sobre o ensino superior e a investigação científica em Moçambique 2004. Maputo: MEC/DCES, 2005.

MOÇAMBIQUE. Lei n. 6/92 de 06 de maio: aprova a Lei do Sistema Nacional de Educação. Maputo: Boletim da República, 1992. p. 8 - 13.

NOA, Francisco. Ensino superior em Moçambique: políticas, formação de quadros e construção da cidadania. 2011. Lisboa: Iscte, 2019, p. 222-238.

PREMUGY, Cassamo I. C. Colectânea de legislação do ensino superior. Maputo: Ministério da Educação, 2012.

ROSÁRIO, Lourenço Joaquim da Costa. Universidades moçambicanas e o futuro de Moçambique. Ensino Superior Unicamp, Campinas, n. 10, 2013, p. 46-55.

SGUISSARDI, Valdemar. Que lugar ocupa a qualidade nas recentes políticas de educação superior? Avaliação: Revista da Avaliação da Educação Superior, Sorocaba, v. 11, n. 3, 2006, p. 69-89.

SGUISSARDI, Valdemar. Regulação estatal versus cultura de avaliação institucional? Avaliação (Campinas), Sorocaba, v. 13, n. 3, 2008. p. 857-862.

SILVA, Eugénio Adolfo Alves da. Direito à educação e educação para todos numa sociedade em desenvolvimento - o caso de Angola. CONGRESSO LUSO-AFROBRASILEIRO DE CIÊNCIAS SOCIAIS, 7, 2004. Anais ... Coimbra: Centro de Estudos Sociais, 2004.

SILVA, Teresa Cruz e. Liberdade acadêmica e ensino superior em Moçambique. Tensões Mundiais, Fortaleza, v. 7, n. 13, 2018, p. 211-234.

TAMBE, Telma Amorgiana Fulane; GÔUVEA, Fernando César Ferreira; TASMERÃO, Aline Silveira. Educação superior em Moçambique: entre o estado e a astúcia do capital. Jornal de Políticas Educacionais, Curitiba, v. 13, 2019, p. 1-22.

TERENCIANO, Fidel; NATHA, Miguel. Ensino superior em Moçambique: evolução e indicadores da avaliação da qualidade. REID, Beira/Moçambique, v. 1, n. 7, 2016, p. 7994.

UNESCO. Conferência Mundial sobre ensino superior 2009: as novas dinâmicas do ensino superior e pesquisas para a mudança e o desenvolvimento social. Comunicado. Paris: Unesco, 2009.

UNIVERSIDADE EDUARDO MONDLANE. Edital - exames de admissão à UEM, ano letivo 2019. Maputo: Universidade Eduardo Mondlane, 2018.

UNIVERSIDADE PEDAGÓGICA. Informação Estatística 2016. Maputo: Gabinete de Planificação e Estudos, 2017a.

UNIVERSIDADE PEDAGÓGICA. Edital - exames de admissão à Universidade Pedagógica, ano académico 2018. Maputo: Universidade Pedagógica, 2017b.

UNIVERSIDADE PEDAGÓGICA. Edital - exames de admissão à Universidade Pedagógica, ano académico 2019. Maputo: Universidade Pedagógica, 2018. 
Leonel Elias Bene é professor na Universidade Púnguè - Extensão de Tete, Moçambique.

Orcid: https://orcid.org/0000-0002-5293-8493.

Endereço: Estrada Nacional n. 7, Campus Universitário de Cambinde, Bairro Matundo, Cidade de Tete - Moçambique.

E-mail: leonel.bene@gmail.com.

Sebastião Juvêncio Rumbane é técnico de administração e finanças na Escola de Jornalismo, Moçambique.

Orcid: https://orcid.org/0000-0002-5139-3452.

Endereço: Avenida Ho Chi Min n. 103, Maputo - Moçambique.

E-mail: rsebastiaojuvencio@gmail.com.

Fabiane Maia Garcia é professora na Universidade Federal do Amazonas.

Orcid: https://orcid.org/0000-0003-0121-0416.

Endereço: Avenida General Rodrigo Octávio, 6200 - 69080-900 - Manaus/AM Brasil.

E-mail: fgarciaead@hotmail.com.

Arminda Rachel Botelho Mourão é professora na Universidade Federal do Amazonas.

Orcid: https://orcid.org/0000-0002-1940-9477.

Endereço: Avenida General Rodrigo Octávio, 6200 - 69080-900 - Manaus/AM Brasil.

E-mail: arachel@uol.com.br.

Critérios de autoria: os autores participaram da concepção da ideia da pesquisa. Leonel Elias Bene e Sebastião Juvêncio Rumbane coletaram, descreveram, analisaram os dados e prepararam a primeira versão. Fabiane Maia Garcia e Arminda Rachel Botelho Mourão participaram da redação e revisão do manuscrito. Os autores discutiram os resultados e contribuíram para a versão final do manuscrito.

Recebido em 27 de novembro de 2021.

Aceito em 13 de janeiro de 2022.

cc) $($ i) $\odot$ 